\title{
Estimation of realized heritability in a selected population using mixed model methods
}

\author{
R. THOMPSON \\ Animal Breeding Research Organisation, Edinburgh, Scotland
}

\begin{abstract}
Summary
The use of mixed model methodology to estimate selection response and realized heritability from selection experiments with no controls is investigated. It has been suggested that the :egression of predicted genetic worth on cumulative selection differential gives an estimate of heritability in a selected population. An assumed value of heritability is used to predict the genetic worth. It is shown for 2 simple designs, using pedigree information on one sex with both discrete and overlapping generations, that the predicted values depend crucially on the assumed value of heritability and not on the heritability in the population. Hence the regression estimator does not give an estimate of heritability in the selected population.
\end{abstract}

Key words : Realized heritability, mixed models.

\author{
Résumé \\ Application des méthodes du modèle mixte à l'estimation de l'héritabilité \\ réalisée dans une population soumise à sélection
}

Cette étude concerne l'application de la méthodologie du modèle mixte à l'estimation de la réponse à la sélection et de l'héritabilité réalisée dans des expériences de sélection sans témoin. Il a été suggéré que la régression de la valeur génétique prédite sur la différentielle cumulée de sélection fournit une estimation de l'héritabilité dans une population soumise à sélection. Une valeur supposée de l'héritabilité est utilisée pour prédire la valeur génétique. On montre, dans 2 dispositifs simples utilisant l'information sur les apparentés dans un seul sexe, avec générations séparées ou chevauchantes, que les valeurs prédites dépendent de façon critique de la valeur supposée de l'héritabilité et non de l'héritabilité dans la population. Par suite, l'estimateur de la régression ne fournit pas une estimation de l'héritabilité dans la population soumise à sélection.

Mots clés : Héritabilité réalisée, modèle mixte.

\section{Introduction}

In experiments to evaluate the response to selection there is often a need to disentangle genetic trend from environmental effects. Two possibilities are to use divergent selection schemes (HILl, 1972a) or to use a control group (HILL, 1972b). 
These designs allow regression of response on selection differential to give estimates of realised heritability (FAlConer, 1981). Blair and PollaK (1984) investigated a third possibility of using mixed model methodology on a selected population to estimate genetic response. Mixed model methodology was first suggested as a means of separating genetic from environmental trends in dairy cattle records subject to culling (HENDERSon et al., 1959). It was later discovered that this technique was a more powerful concept useiful in problems of prediction of breeding values corrected for fixed effects (HENDERSON, 1973) and estimation of variance components by maximum likelihood (HARVILLE, 1977).

Blair \& PollaK (1984), by analogy with selection experiments, suggested using the regression of predicted yearly genetic means on the cumulative selection differential, $b_{\mathrm{BP}}$, as an estimate of realised heritability. For one particular sheep selection experiment they state the standard error of $b_{\mathrm{BP}}$ is about the same as that for an estimate based on using both selected and control flock data. If true, this would be a remarkable result showing that selection experiments could be more efficient without control lines than with control lines. BLAIR \& Pollak (1984) noted that the results and conclusions may be influenced by the heritability value used in the prediction process. It seemed useful to quantify the extent of this influence. Partly to see if it was merely a numerical artefact, and partly because in one simple case, briefly discussed by ТномрSON, $1979, b_{\mathrm{BP}}$ is exactly the value of heritability used to predict the breeding values.

By algebraically considering 2 simple designs it is shown that the regression coefficient does not give an estimate of heritability in the selected population. The designs considered in detail are partly motivated by actual selection experiments in this institute (Purser, 1980), comments by Blair \& PollaK (1984) and last, but not least, algebraic simplicity. In both designs a pool of dams of constant genetic merit is assumed and pedigree information on the female side is ignored (a common occurence in dairy sire evaluation). Design $I$ is a design where in each of $T$ years sn males are measured and after the first year $n$ sons of each of $s$ sires are measured. In order to reduce genetic drift, suppose there is within family selection on the basis of the measured trait so that only one son of elach sire is used as a sire. This design has no overlap between generations.

In design II suppose again sn males are measured in year 1. Then suppose s sires are selected using the measured trait and they each have $n$ sons in year 2 and in year 3. One son is selected from each of the s sire families in year 2 and has $\mathbf{n}$ sons in year 3. There is now overlap is year 3 with offspring from sires of age 1 and 2 .

\section{Analysis}

\section{A. Design I}

The observation and predicted additive genetic value for the ith animal in year 1 will be written as $y_{i}$ and $s_{i}(i=1, \ldots, s n)$ and let $i=1, \ldots, s$ represent sires that have offspring, also $y_{t i j}$ and $s_{t i j}$ represent the measurement and predicted value for the $j$ th descendant of sire $i$ in year $t$, and let $j=1$ denote the individuals that have offspring. 
Then suppose

$$
\begin{aligned}
& \sum_{i=1}^{s n} y_{l i}=s n \bar{y}_{1}, \sum_{i=1}^{\infty} y_{i l}=s \bar{y}_{1}^{*}, \sum_{i, j} y_{t i j}=s n \bar{y}_{t}, \sum_{i} y_{t i l}=s \bar{y}_{t}^{*} \\
& \sum_{i=1}^{s n} s_{l i}=s n \bar{s}_{1}, \sum_{i=1}^{\not N} s_{i 1}=s \bar{s}_{1}^{*}, \sum_{j} s_{t i j}=n \bar{s}_{t i}, \sum_{i} s_{t i}=s \bar{s}_{t}, \sum_{i} s_{t i l}=\bar{s}_{t}^{*}
\end{aligned}
$$

It is assumed that there are fixed effects, $m_{t}$, associated with measurements on the t-th year and a residual variance $\sigma_{e}^{2}$ associated with each observation. When there is no selection the genetic covariances between sires can be derived from the coefficients of parentage and the additive genetic variance, $\sigma_{\mathrm{A}}^{2}$, (KEMPTHORNE, 1957) and this variance matrix will be denoted by $A \sigma_{A}^{2}$. It is well known that the genetic variances change with selection, but if $\sigma_{\text {AS }}^{2}$ is thought of as the additive genetic variance in the base population before selection and selection is on traits included in the model, then a conditional argument can be used to show that operationally one can use $A \sigma^{2}{ }_{A S}$ as the genetic variance matrix when estimating fixed effects (HENDERSon et al., 1959) and when estimating $\sigma_{\text {AS }}^{2}$ (CURnow, 1961 ; ThOMPSON, 1979).

In the appendix, mixed model equations are given and manipulated to show that estimators of genetic merit and year effects for this model are :

$$
\begin{aligned}
& \bar{s}_{1}=0, m_{1}=\bar{y}_{1} \\
& \bar{s}_{2}=(1 / 2) h^{2}\left(\bar{y}_{1}^{*}-\bar{y}_{1}\right), m_{2}=\bar{y}_{2}-(1 / 2) h^{2}\left(\bar{y}_{1}^{*}-\bar{y}_{1}\right) \\
& \bar{s}_{t+1}=(1 / 2) h_{w}^{2}\left(\tilde{y}_{t}^{*}-\bar{y}_{t}\right)+1 / 2 \bar{s}_{t}, m_{t}=\bar{y}_{t}-\bar{s}_{t}
\end{aligned}
$$

where $h^{2}$ is a prior estimate of heritability and $h_{w}^{2}=3 h^{2} /\left(4-h^{2}\right)$ is a within half-sib family estimate of heritability.

Blair \& PollaK (1984) suggest regressing $\bar{s}_{\mathrm{t}}$ on the cumulative selection differential. For this design the cumulative selection differential, $\mathrm{CSD}_{1}$, at the end of year $t$ satisfies $\operatorname{CSD}_{\mathrm{t}}=(1 / 2) \operatorname{CSD}_{\mathrm{t}-1}+(1 / 2)\left(\overline{\mathrm{y}}_{\mathrm{t}}^{*}-\bar{y}_{\mathrm{t}}\right)$ with $\operatorname{CSD}_{\mathrm{o}}=0$.

Then :

$$
\begin{aligned}
& \operatorname{CSD}_{\mathrm{t}}-(1 / 2) \operatorname{CSD}_{\mathrm{t}-1}=(1 / 2)\left(\overline{\mathrm{y}}_{\mathrm{t}}^{*}-\overline{\mathrm{y}}_{\mathrm{t}}\right) \\
& \overline{\mathrm{s}}_{\mathrm{t}+1}=\mathrm{h}_{\mathrm{w}}^{2}\left(\operatorname{CSD}_{\mathrm{t}}-(1 / 2) \operatorname{CSD}_{\mathrm{t}-1}\right)+(1 / 2) \overline{\mathrm{s}}_{\mathrm{t}} \\
& \overline{\mathrm{s}}_{\mathrm{t}}=\mathrm{h}_{\mathrm{w}}^{2}\left(\operatorname{CSD}_{\mathrm{t}-1}-(1 / 2) \operatorname{CSD}_{\mathrm{t}-2}\right)+(1 / 2) \overline{\mathrm{s}}_{\mathrm{t}-1} \\
& \overline{\mathrm{s}}_{3}=\mathrm{h}_{\mathrm{w}}^{2}\left(\operatorname{CSD}_{2}-(1 / 2) \operatorname{CSD}_{1}\right)+(1 / 2) \overline{\mathrm{s}}_{2} \\
& \overline{\mathrm{s}}_{\mathrm{t}+1}=\mathrm{h}_{\mathrm{w}}^{2}\left(\operatorname{CSD}_{\mathrm{t}}-\left(1 / 2^{\mathrm{t}-1}\right) \operatorname{CSD}_{1}\right)+\left(1 / 2^{\mathrm{t}-1}\right) \overline{\mathrm{s}}_{2} \\
& \overline{\mathrm{s}}_{\mathrm{t}+1}=\mathrm{h}_{\mathrm{w}}^{2} \operatorname{CSD}_{\mathrm{t}}+\left(1 / 2^{\mathrm{t}-1}\right)\left[\mathrm{h}^{2}-\mathrm{h}_{\mathrm{w}}^{2}\right] \operatorname{CSD}_{1}
\end{aligned}
$$

The predicted mean genetic merit is a multiple of the cumulative selection differential plus a correction term for the difference in heritabilities in the first and succeeding years that halves each year. The regression of $\bar{s}_{t+1}$ on $\operatorname{CSD}_{i}$ gives a regression coefficient lying between $h_{w}^{2}$ and $h^{2}$ and tending to $h_{w}^{2}$ as $t$ increases.

\section{B. Design II}

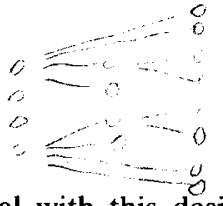

A slight extension of the notation is needed to deal with this design because sires have sons in 2 years. Let $y_{13 \mathrm{jij}}$ be measurements in year 3 on sons of males in year 1 , with a similar definition of sire effects. 
Also let

$\sum_{\mathrm{ij}} \mathrm{y}_{13 \mathrm{ij}}=\mathrm{sny} \bar{y}_{13}, \sum_{\mathrm{j}} \mathrm{s}_{13 \mathrm{ij}}=\mathrm{ns} \bar{s}_{13 \mathrm{i}}, \sum_{\mathrm{i}} \overline{\mathrm{s}}_{13 \mathrm{i}}=\mathrm{s} \bar{s}_{13}$, and

$z\left(h^{2}\right)=\left(\bar{y}_{13}-\bar{y}_{1}\right)+(1 / 2) h_{w}^{2}\left(\bar{y}_{2}^{*}-\bar{y}_{2}\right)-(1 / 4) h^{2}\left(\bar{y}_{1}^{*}-\bar{y}_{1}\right)$

It can be shown from the results in the appendix, that estimates of genetic merit using an assumed value of heritability, $\mathbf{h}^{2}$, are

$$
\begin{aligned}
& \bar{s}_{1}=q_{1} z\left(h^{2}\right) \\
& \bar{s}_{2}=(1 / 2) h^{2}\left(\bar{y}_{1}^{*}-\bar{y}_{1}\right)+q_{2} z\left(h^{2}\right) \\
& \left(\bar{s}_{13}+\bar{s}_{3}\right) / 2=(3 / 8) h^{2}\left(\bar{y}_{1}^{*}-\bar{y}_{1}\right)+(1 / 4) h_{w}^{2}\left(\bar{y}_{2}^{*}-\bar{y}_{2}\right)+q_{3} z\left(h^{2}\right)
\end{aligned}
$$

The terms, $q_{1}, q_{2}, q_{3}$ can be found from functions of $n$ and $h^{2}$. In table 1 are given values of $q_{1}, q_{2}$ and $q_{3}$ for various values of $n$ and $h^{2}$ showing that $q_{1}, q_{2}, q_{3}$ increase as $h^{2}$ increases and that $q_{1}$ and $q_{3}$ decrease and $q_{2}$ increases as $n$ increases.

TABLE 1

Values of $q_{1}, q_{2}$ and $q_{3}$ for various values of assumed heritability $\left(h^{2}\right)$ and family size $(n)$

\begin{tabular}{cc|r|r|r|r}
\hline \hline $\mathrm{h}^{2}$ & $\mathrm{n}$ & $\mathrm{q}_{1}$ & $\mathrm{q}_{2}$ & $\mathrm{q}_{3}$ \\
& & $\mathrm{n}$ & 0.013 & -0.013 & 0.000 \\
0.1 & 2 & 0.012 & -0.007 & 0.000 \\
& 5 & 0.012 & 0.100 & 0.000 \\
& 10 & 0.011 & 0.035 & -0.002 \\
& 20 & 0.010 & 0.078 & -0.002 \\
& 30 & 0.009 & 0.114 & -0.002 \\
\hline \multirow{5}{*}{0.3} & $2+2$ & 0.039 & -0.039 & 0.000 \\
& 2 & 0.038 & -0.025 & -0.001 \\
& 5 & 0.035 & 0.014 & -0.003 \\
& 10 & 0.031 & 0.066 & -0.006 \\
& 20 & 0.025 & 0.142 & -0.010 \\
& 30 & 0.021 & 0.194 & -0.013 \\
\hline \multirow{5}{*}{0.5} & 1 & 0.067 & -0.067 & 0.000 \\
& 2 & 0.064 & -0.048 & -0.002 \\
& 5 & 0.058 & 0.000 & -0.006 \\
& 10 & 0.050 & 0.063 & -0.012 \\
& 20 & 0.039 & 0.147 & -0.020 \\
& 30 & 0.032 & 0.201 & -0.025 \\
\hline
\end{tabular}

The cumulative selection differentials in this case are $\operatorname{CSD}_{1}=(1 / 2)\left(\bar{y}_{1}^{*}-\bar{y}_{1}\right)$ and $\operatorname{CSD}_{2}=(3 / 8)\left(\bar{y}_{1}^{*}-\bar{y}_{1}\right)+(1 / 4)\left(\bar{y}_{2}^{*}-\bar{y}_{2}\right)$ so that $\overline{\mathrm{s}}_{1+1}=\mathrm{h}_{\mathrm{w}}^{2} \operatorname{CSD}_{1}+$ $\left(1 / 2^{t-1}\right)\left(h^{2}-h_{w}^{2}\right) C S D_{1}+q_{t+1} z\left(h^{2}\right)$, the same form as for design I with the addition of an extra term $q_{t+1} z\left(h^{2}\right)$.

In order to interpret the $\mathrm{z}\left(\mathrm{h}^{2}\right)$ term, it is seen, by considering the year effects estimators from design $I$, that there are in design II two estimates of $m_{3}$ readily available i.e. $\mathrm{m}_{3}=\bar{y}_{3}-(1 / 2) \mathrm{h}_{\mathrm{w}}^{2}\left(\overline{\mathrm{y}}_{2}^{*}-\bar{y}_{2}\right)-(1 / 4) \mathrm{h}^{2}\left(\overline{\mathrm{y}}_{1}^{*}-\overline{\mathrm{y}}_{1}\right)$ and $\mathrm{m}_{3}=\overline{\mathrm{y}}_{13}-(1 /$ 2) $h^{2}\left(\bar{y}_{1}^{*}-\bar{y}_{1}\right)$. The discrepancy between these 2 values is $z\left(h^{2}\right)$. This is used in the mixed model approach to provide information on $m_{1}$ and $m_{2}$, and $q_{1}$ and $q_{2}$ can be 
interpreted as measures of the information that $\mathrm{z}\left(\mathrm{h}^{2}\right)$ provides on $\mathrm{m}_{1}$ and $\mathrm{m}_{2}$. Alternatively consideration of repeat-mating designs (for example, Giesbrecht \& KempthorNe, 1965) suggest estimating $h_{\mathrm{s}}^{2}=\sigma_{\mathrm{AS}}^{2} /\left(\sigma_{\mathrm{e}}^{2}+\sigma_{\mathrm{AS}}^{2}\right)$ the heritability in the population by choosing $h_{s}^{2}$ so that $\mathrm{z}\left(\mathrm{h}_{\mathrm{s}}^{2}\right)=0$.

As the expected value of $\bar{y}_{3}-\bar{y}_{13}$ is $1 / 2 h_{s w}{ }^{2}\left(\bar{y}_{2}^{*}-\bar{y}_{2}\right)-(1 / 4) h_{s}^{2}\left(\bar{y}_{1}^{*}-\bar{y}_{1}\right)$ the expected value of $b_{B P}, E\left(b_{B P}\right)$;is a function of $h^{2}, n, h_{s}^{2}$ and the selection differentials. When $\left(\bar{y}_{1}^{*}-\bar{y}_{1}\right)=\left(\bar{y}_{2}^{*}-\bar{y}_{2}\right)$ then $n$ and $h_{s}^{2}$ have little effect on $E\left(b_{B P}\right)$. For instance for $\mathrm{n}=30$ and $h_{s}^{2}=0,1$ then $E\left(b_{B P}\right)=0.094,0.291$ and 0.493 when $h^{2}=0.1,0.3$ and 0.5 and when $n=30$ and $h_{s}^{2}=0.5$ then $E\left(b_{B P}\right)=0.088,0.280$ and 0.483 . Again showing the crucial dependence of $b_{B P}$ on the assumed value of heritability $h^{2}$ and not on the population value $\mathbf{h}_{\mathrm{s}}^{2}$ :

\section{Discussion}

In 2 simple designs it has been shown that $b_{\mathrm{BP}}$ does not estimate heritability in the selected population. This should not be surprising in design I because of the confounding between years and generations. It is worrying in design II when a natural estimator of heritability is available.

Actual selection experiments, including the one considered by BlaIR \& Pollak (1984), are often more complicated than these 2 designs. For instance (i) mass or index selection could be carried out, (ii) measurements and pedigrees on females might be available, (iii) there could be more overlapping of generations, (iv) other effects such as sage of dam, partially confounded with generations need to be estimated, ( $v$ ) it is rare to have equal family sizes. To take account of (i) one could try to explain $s_{t}$ in terms of selection differentials within and between families. But if the phenotypic selectional differentials were used one would expect $b_{\mathrm{BP}}$ to be larger than $h_{w}^{2}$, but not as large as $h^{2}$. The actual magnitude depends on $h_{s}^{2}$ and the actual selection scheme. The major consequence of (ii) would be to reduce $h_{w}^{2}$ to within full-sib heritability $h^{2} /\left(2-h^{2}\right)$. With (iii) the definition of the cumulative selection differential needs more care and there is the need to take account of the cumulative selection differential in the contemporaries (PURSER, 1980 ; JAMES, 1977). Both (iv) and (v) add some complexity to the analysis. None of these reasons suggest that $b_{\mathrm{BP}}$ will ever be a reasonable estimator of heritability from selection experiments without control.

As the estimated means $\bar{s}_{t}$ are derived from selection differentials they are not observed responses. Therefore the variances of $\bar{s}_{\mathrm{t}}$ are not expressible in terms of the drift variances HILl (1972a) derives for observed responses as BLAIR \& Pollak (1984) assume.

Obviously when the value of $h^{2}$ used in predicting $\bar{s}_{t}$ is the value in the population then the calculation of $\bar{s}_{\mathrm{t}}$ and $\mathrm{b}_{\mathrm{BP}}$ can be useful as a monitoring device for the selection scheme and can be thought of as a sophisticated version of the predicted response $h^{2} \mathrm{CSD}$ rather than as a measured response to selection. However in selection experiments there will usually be the need to generate internally some evidence or tests for the value of parameters in the model including heritability. Just because some prediction of $\bar{s}_{t}$ is available from selection experiments without controls using mixed model methods does not seem to me sufficient grounds for recommending the use of such designs. 
Of course there are other methods of estimating heritability and some of these are related to equating sums of squares of predicted values to their expectation (THOMPSON, 1977 ; SORENSEN \& KeNNEDY, 1984). However just because estimates are available does not imply that designs without controls are particularly efficient.

As a simple example consider 2 designs for 2 generations with $\mathrm{N}$ males measured in the first generation. In the first design offspring are raised from the best $2 \mathrm{n}$ males and heritability estimated by regression of offspring on parent. In the second, $n$ males are chosen at random (a control) and the best $\mathrm{n}$ from the remaining $\mathrm{N}$.' In this design 2 natural estimates are possible, one by comparing the response and selection differential and another by regression of offspring on parent. The variances of the 3 estimators are then inversely proportional to $(1-i(i-x)), i^{\prime 2} / 2$ and $1-i^{\prime}\left(i^{\prime}-x^{\prime}\right) / 2+i^{\prime 2 / 2}$ (for example HiLl (1970)) where $x$ and $z$ are the truncation point and ordinate for a normal distribution with a proportion $p=2 n / N$ truncated and $i=z / p$ and $x^{\prime}, z^{\prime}, i^{\prime}$ are the corresponding values for $p^{\prime}=n /(N-n)$. For example with $n=10$ and $N=100$ then relative to the variance estimator in the first design, the two estimators in the second design variance $0.68 / 4.57=0.15$ and $0.49 / 4.57=0.11$ showing that the design with a control provides almost 10 times as much information on heritability as the design without a control.

Received January 2, 1986.

Accepted May 6, 1986.

\section{References}

Blair H.T., Pollak E.J., 1984. Estimation of genetic trend in a selected population with and without the use of a control population. J. Anim. Sci., 58, 878-886.

CuRnow R.N., 1961. The estimation of repeatability and heritability from records subject to culling. Biometrics, 17, 553-556.

Falconer D.S., 1981. Introduction to Genetics Statistics ( $2^{\text {nd }}$ ed.). 340 pp., Longman, London.

Giesbrecht F., KempthorNe O., 1965. Estimation of a repeat mating design for estimating environmental and genetic trends. Biometrics, 21, 63-85.

HARVILLE D.A., 1977. Maximum likelihood approaches to variance component estimation and to related problems. J. Am. Stat. Assoc., 72, 320-338.

Henderson C.R., 1973. Sire evaluation and genetic trends. In Proceeding of the Animal Breeding and Genetics Symposium in Honor of Dr. J.L. Lush, 111, 10-41. ASAS and ADSA, Champaign.

Henderson C.R., Kempthorne O., Searle S.R., Von Krosigk C.N., 1959. Estimation of environmental and genetic trends from records subject to culling. Biometrics, 13, 192-218.

Hill W.G., 1970. Design of experiments to estimate heritability by regression of offspring on selected parents. Biometrics, 26, 566-571.

HrLl W.G., 1972a. Estimation of realized heritabilities from selected experiments. I. Divergent selection. Biometrics, 28, 747-765.

HIL. W.G., 1972b. Estimation of realized heritabilities from selection experiments. II. Selection in one direction. Biometrics, 28, 767-780.

JAmES J.W., 1977. A note on selection differential and generation length when generations overlap. Anim. Prod., 24, 109-112.

Kempthorne O., 1957. An introduction to genetic statistics. 545 pp., Wiley, New York. 
PURSER A.E., 1980. Comparison of expected and realised responses in three sheep selection experiments. In RoBertson A. (ed.), "Selection Experiments in Laboratory and Domestic Animals», 21-30. Commonwealth Agricultural Bureaux, Edinburgh.

SoRensen D.A., Kennedy B.W., 1984. Estimation of response to selection using least squares and mixed model methodology. J. Anim. Sci., 58, 1097-1106.

Thомpson R., 1977. The estimation of heritability with unbalanced data. II. Data available on more than two zenerations. Biometrics, 33, 497-504.

Thompson R., 1979. Sire Evaluation. Biometrics, 35, 339-353.

\section{Appendix}

In this appendix estimators of year effects and mean genetic merit are derived for the two designs.

\section{Design I}

Mixed model equations (HENDERSon, 1973) for this design have a simple form because of the pattern in $A^{-1}$. Let $G=\sigma_{e}^{2} / \sigma_{A}^{2}=\left(1-h^{2}\right) / h^{2}, H=G / 3$ and $F=1+4 H=\left(4-h^{2}\right) / 3 h^{2}=1 / h_{w}^{2}$, then estimators of $m_{i}, s_{1 i}$ and $S_{t i j}$ satisfy

$$
\begin{aligned}
& \mathrm{snm}_{1}+\mathrm{sns}_{\mathbf{1}}=\mathrm{sny}_{1} \\
& \operatorname{snm}_{\mathrm{t}}+\operatorname{sn} \overline{\mathbf{s}}_{\mathrm{t}}=\operatorname{sny}_{\mathrm{t}} \quad(\mathrm{t}=2, \ldots, \mathrm{T}) \\
& \mathrm{m}_{1}+(1+\mathrm{G}+\mathrm{nH}) \mathrm{s}_{\mathrm{li}}-2 \mathrm{nH}_{\mathrm{i}} \mathrm{s}_{2 \mathrm{i}}=\mathrm{y}_{\mathrm{li}} \quad(\mathrm{i}=1, \ldots, \mathrm{s}) \\
& \mathrm{m}_{1}+(1+\mathrm{G}) \mathrm{s}_{1 \mathrm{i}}=\mathrm{y}_{\mathrm{li}} \quad(\mathrm{i}=\mathrm{s}+1, \ldots, \mathrm{sn}) \\
& \mathrm{m}_{\mathrm{t}}-2 \mathrm{Hs}_{(\mathrm{t}-1) \mathrm{il}}+(\mathrm{F}+\mathrm{nH}) \mathrm{s}_{\mathrm{til}}-2 \mathrm{nHs}_{(\mathrm{t}+1) \mathrm{il}}=\mathrm{y}_{\mathrm{til}} \quad(\mathrm{t}=2, \ldots, \mathrm{T}-1) \\
& \mathrm{m}_{\mathrm{t}}-2 \mathrm{Hs}_{(\mathrm{t}-1) \mathrm{i}}+\mathrm{Fs}_{\mathrm{tij}}=\mathrm{y}_{\mathrm{tij}} \quad(\mathrm{t}=2, \ldots, \mathrm{T}-1),(\mathrm{j}=2, \ldots, \mathrm{n}) \\
& \mathrm{m}_{\mathrm{i}}-2 \mathrm{Hs}_{(\mathrm{T}-1) \mathrm{il}}+\mathrm{Fs}_{\mathrm{Tij}}=\mathrm{y}_{\mathrm{Tij}} \\
& -1=
\end{aligned}
$$

These equations can be thought of as least squares equations with extra coefficients, (i) for males with no sons ( $G$ or $F-1$ depending on whether their fathers are measured), (ii) for males with sons $(\mathrm{G}+\mathrm{nH}$ or $\mathrm{F} / \mathrm{H}+\mathrm{nH}$ depending on whether fathers are measured), (iii) for sires and sons $(-2 \mathrm{H})$.

By adding together equations and dividing by sn it can be shown that

Hense

$$
\begin{aligned}
& \mathrm{m}_{1}+(1+\mathrm{G}) \overline{\mathrm{s}}_{1}+\mathrm{Hs}_{1}^{*}-2 \mathrm{H} \overline{\mathrm{s}}_{2}=\overline{\mathrm{y}}_{1} \\
& \mathrm{~m}_{\mathrm{t}}-2 \mathrm{H} \bar{s}_{\mathrm{t}-1}^{*}+\mathrm{Fs}_{\mathrm{t}}+\mathbf{H} \bar{s}_{\mathrm{t}}^{*}-2 \mathrm{H} \bar{s}_{\mathrm{t}-1}=\bar{y}_{\mathrm{t}}=\mathrm{w}_{\mathrm{t}} \\
& \mathrm{m}_{\mathrm{T}}-2 \mathrm{H}_{\mathrm{s}-1}^{*}+\mathrm{Fs}_{\mathrm{T}}=\bar{y}_{\mathrm{T}} \text { : } \\
& { }^{*}(\mathrm{~F}-1) \overline{\mathrm{s}}_{\mathrm{T}}=2 \mathrm{H} \overline{\mathrm{s}}_{\mathrm{T}-1}^{*} \text { or } 2 \overline{\mathrm{s}}_{\mathrm{T}}=\overline{\mathrm{s}}_{\mathrm{T}-1}^{*} \\
& (F-1) \bar{s}_{t}-2 H \bar{s}_{t-1}^{*}=H\left(\bar{s}_{t}^{*}-2 \bar{s}_{t+1}\right) \\
& \mathrm{G} \overline{\mathrm{s}}_{1}=\mathrm{H}\left(\overline{\mathrm{s}}_{1}^{*}-2 \overline{\mathrm{s}}_{2}\right) \\
& \text { or } \begin{aligned}
2 \bar{s}_{\mathrm{t}}= & \bar{s}_{\mathrm{t}-1}^{*} \\
& \bar{s}_{1}=0
\end{aligned} \\
& (\mathrm{t}=2, \ldots, \mathrm{T})
\end{aligned}
$$


By adding together equations for animals not selected it can be shown that

$$
\begin{aligned}
& s(n-1) m_{1}+(1+G)\left(s n \bar{s}_{1}-s \vec{s}_{1}^{*}\right)=s n \bar{y}_{1}-s \bar{y}_{1}^{*} \\
& s(n-1) m_{1}-2 H s(n-1) \bar{s}_{t-1}+F\left(s n \bar{s}_{t}-s \bar{s}_{t}^{*}\right)=s n \bar{y}_{t}-s \bar{y}_{i}^{*}
\end{aligned}
$$

or $w=y_{1}, \because$

$$
\begin{aligned}
& (n-1)\left(\bar{y}_{1}-\bar{s}_{1}\right)+(1+G)\left(n \bar{s}_{1}-\bar{s}_{1}^{*}\right)=n \bar{y}_{1}-\bar{y}_{i}^{*} \\
& (n-1)\left(\bar{y}_{t}-\bar{s}_{t}\right)-2 H(n-1) \bar{s}_{t-1}^{*}+F\left(n \bar{s}_{t}-\bar{s}_{t}^{*}\right)=n \bar{y}_{t}-\bar{y}_{t}^{*}
\end{aligned}
$$

and

$$
\begin{aligned}
& (1+G) \overline{\mathrm{s}}_{1}^{*}=\left(\bar{y}_{1}^{*}-\tilde{y}_{1}\right) \\
& F \bar{s}_{\mathrm{t}}^{*}=\left(\bar{y}_{\mathrm{t}}^{*}-\bar{y}_{\mathrm{t}}\right)+\mathrm{F} \overline{\mathrm{s}}_{\mathrm{t}}
\end{aligned}
$$

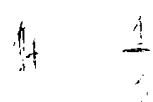

Hence

and

$$
\overline{\mathbf{s}}_{1}^{*}=\mathrm{h}^{2}\left(\overline{\mathrm{y}}_{1}^{*}-\overline{\mathrm{y}}_{1}\right)
$$

$$
\overline{\mathrm{s}}_{\mathrm{t}}^{*}=\mathrm{h}_{\mathrm{w}}^{2}\left(\overline{\mathrm{y}}_{\mathrm{t}}^{*}-\overline{\mathrm{y}}_{\mathrm{t}}\right)+\overline{\mathrm{s}}_{\mathrm{t}}
$$

so that the mean merit of animals in year $t$ is half the mean merit of their fathers. The merit of selected sires in year $t$ is the mean merit in year $t$ plus the selection differential times a measure of heritability.

\section{Design II}

The mixed model equations are now

$$
\begin{aligned}
& \operatorname{snm}_{1}+\operatorname{sn} \bar{s}_{1}=\operatorname{sny} \bar{y}_{1} \\
& \mathbf{s n m}_{2}+\mathbf{s n \overline { s } _ { 2 }}=\mathbf{s n y} \bar{y}_{2} \\
& 2 \mathrm{snm}_{3}+\operatorname{sn}\left(\overline{\mathrm{s}}_{13}+\overline{\mathrm{s}}_{3}\right)=\operatorname{sn}\left(\overline{\mathrm{y}}_{13}+\overline{\mathrm{y}}_{2}\right) \\
& \mathrm{m}_{1}+(1+\mathrm{G}+2 \mathrm{nH}) \mathrm{s}_{1 \mathrm{i}}-2 \mathrm{nH}_{2 \mathrm{i}}-2 \mathrm{nH} \bar{s}_{13 \mathrm{i}}=\mathrm{y}_{\mathrm{lj}} \\
& \mathrm{m}_{\mathrm{l}}+(1+\mathrm{G}) \mathrm{s}_{\mathrm{li}}=\mathrm{y}_{\mathrm{li}} \\
& \mathrm{m}_{2}-2 \mathrm{Hs}_{1 \mathrm{i}}+(\mathrm{F}+\mathrm{nH}) \mathrm{s}_{2 \mathrm{il}}-2 \mathrm{nH} \bar{s}_{3 \mathrm{i}}=\mathrm{y}_{2 \mathrm{il}} \\
& \mathrm{m}_{2}-2 \mathrm{Hs}_{\mathrm{ii}}+\mathrm{Fs}_{2 \mathrm{ij}}=\mathrm{y}_{2 \mathrm{ij}} \\
& \mathrm{m}_{3}-2 \mathrm{Hs}_{1 \mathrm{i}}+\mathrm{Fs}_{1 \mathrm{ijj}}=\mathrm{y}_{13 \mathrm{ij}} \\
& \mathrm{m}_{3}-2 \mathrm{Hs}_{2 \mathrm{il}}+\mathrm{Fs}_{3 \mathrm{ij}}=\mathrm{y}_{3 \mathrm{ij}}
\end{aligned}
$$$$
(\mathrm{i}=1, \ldots, \mathrm{s})
$$$$
(\mathrm{i}=\mathbf{s}+1, \ldots, \mathrm{sn})
$$

Eliminating effects for males with no progeny and adding within generations it can be shown that

$$
\begin{aligned}
& (1+n G) m_{1}+(1+G) \bar{s}_{1}^{*}=n G \bar{y}_{1}+\bar{y}_{1}^{*} \\
& (1+4 n G) m_{2}+2(n-1) H \bar{s}_{1}^{*}+F \bar{s}_{2}^{*}=4 n H \bar{y}_{2}+\bar{y}_{2}^{*} \\
& 4 m_{3}+\left(\bar{s}_{1}^{*}+\bar{s}_{2}^{*}\right)=2\left(\bar{y}_{13}+\bar{y}_{3}\right) \\
& m_{2}+(2 H n / F) m_{3}-2 H \bar{s}_{1}^{*}+(F+n H / F) \bar{s}_{2}^{*}=\bar{y}_{2}^{*}+(2 H n / F) \bar{y}_{3} \\
& \left.m_{1}+2 H(n-1) / F\right) m_{2}+(2 H n / F) m_{3}+[F+(2 n-1) H / F] \bar{s}_{1}^{*}-2 H \bar{s}_{2}^{*}= \\
& y_{1}^{*}+(2 H n / F) \bar{y}_{2}-(2 H / F) \bar{y}_{2}^{*}+(2 H n / F) \bar{y}_{13}
\end{aligned}
$$


Manipulating these equations (A1-5) it can be shown that

$$
\begin{aligned}
& \mathrm{m}_{1}=\overline{\mathrm{y}}_{1}-\mathrm{q}_{1} \mathrm{z}\left(\mathrm{h}^{2}\right) \\
& \mathrm{m}_{2}=\overline{\mathrm{y}}_{2}-(1 / 2) \mathrm{h}^{2}\left(\overline{\mathrm{y}}_{1}^{*}-\overline{\mathrm{y}}_{1}\right)-\mathrm{q}_{2} \mathrm{z}\left(\mathrm{h}^{2}\right) \\
& \mathrm{m}_{3}=\left(\overline{\mathrm{y}}_{13}+\overline{\mathrm{y}}_{3}\right) / 2-(3 / 8) \mathrm{h}^{2}\left(\overline{\mathrm{y}}_{1}^{*}-\overline{\mathrm{y}}_{1}\right)-(1 / 4) h_{\mathrm{w}}^{2}\left(\overline{\mathrm{y}}_{2}^{*}-\overline{\mathrm{y}}_{2}\right)-\mathrm{q}_{3} \mathrm{z}\left(\mathrm{h}^{2}\right) \\
& \overline{\mathrm{s}}_{1}^{*}=\mathrm{h}^{2}\left(\overline{\mathrm{y}}_{1}^{*}-\overline{\mathrm{y}}_{1}\right)-\mathrm{q}_{4} \mathrm{z}\left(\mathrm{h}^{2}\right) \\
& \overline{\mathrm{s}}_{2}^{*}=(1 / 2) \mathrm{h}^{2}\left(\overline{\mathrm{y}}_{1}^{*}-\overline{\mathrm{y}}_{1}\right)+\mathrm{h}_{\mathrm{w}}^{2}\left(\mathrm{y}_{2}^{*}-\overline{\mathrm{y}}_{2}\right)-\mathrm{q}_{\mathrm{s}} \mathrm{z}\left(\mathrm{h}_{2}\right)
\end{aligned}
$$

where $z\left(h^{2}\right)$ is defined in equation (1) and $q_{1}, q_{2}, q_{3}, q_{4}$ and $q_{5}$ are solutions for $m_{1}$, $\mathrm{m}_{2}, \mathrm{~m}_{3}, \overline{\mathrm{s}}_{1}^{*}$ and $\overline{\mathrm{s}}_{2}^{*}$ in equation (A1) - (A5) with $\overline{\mathrm{y}}_{1}=\overline{\mathrm{y}}_{1}^{*}=\overline{\mathrm{y}}_{2}=\overline{\mathrm{y}}_{2}^{*}=0$ and $\overline{\mathrm{y}}_{13}=\overline{\mathrm{y}}_{3}=$ $-1 / 2$.

Hence the $q$ values are functions of $h^{2}$ and The mean genetic values can be derived from the estimates of $m_{1}, m_{2}$ and $m_{3}$ and are given in equation (2) - (4). 